\title{
Deep Drawability and Recrystallization Texture of Rephosphorized Al-killed High Strength Cold-rolled Steel*
}

\author{
By Satoshi ONO**, Takayoshi SHIMOMURA**, Koichi OSAWA** \\ and Kazuo MATSUDO**
}

\begin{abstract}
Synopsis
The deep drawability and the recrystallization texture of rephosphorized $\mathrm{Al}-k i l l e d$ high strength steels $(\mathrm{P}: \sim 0.07 \%$ ) were studied as compared with those of a conventional Al-killed steel (P: 0.016\%).

$A$ rephosphorized Al-killed steel shows the peak $\bar{r}$-value at a certain heating rate in annealing as well as a conventional Al-killed steel. However, phosphorus slightly weakens the retardation effect of $\mathrm{AlN}$ on recrystallization, which results in a lower $\bar{r}$-value and a lower grain elongation ratio. The preferred orientation of a rephosphorized Al-killed steel is $\{111\}$ $\langle 112\rangle$ though that of a conventional Al-killed steel is $\{111\}\langle 110\rangle$.

These results are discussed by taking into account the interaction between phosphorus and $\mathrm{AlN}$ precipitation behavior.
\end{abstract}

\section{Introduction}

Yoshida et al. ${ }^{1)}$ showed first that the $\bar{r}$-value of a low carbon rimmed steel was improved by adding phosphorus and by annealing its cold-rolled sheet in a decarburizing atmosphere. Since then, only a few studies have been conducted concerning the effect of phosphorus on the deep drawability of a cold-rolled steel sheet. ${ }^{2,3)}$

In recent years, various high strength cold-rolled steels have been energetically developed to meet the car-makers' demands for safety and weight reduction of auto-bodies. Among them, rephosphorized steels with a tensile strength of 35 to $40 \mathrm{kgf} / \mathrm{mm}^{2}$ are now put into practical use for inner and outer panels, since phosphorus has a high solid solution hardening effect and moreover has a preferable effect on the deep drawability in addition to its low cost.

This practical application of rephosphorized steels has stimulated the study on the role of phosphorus in the formation of the recrystallization texture of coldrolled steels. Especially, $\mathrm{Hu}^{\mathbf{4}, 5)}$ and the present authors $^{6,7)}$ have made detailed studies about it. These studies have been made mainly in rimmed steels and also in Al-killed steels with AlN precipitated prior to cold rolling. On the other hand, as for the study on the Al-killed steel without AlN precipitation treatment prior to cold rolling, the present authors ${ }^{6}$ ) have shown that phosphorus lowers the grain elongation ratio with little effect on the $\bar{r}$-value, and Takahashi and $\mathrm{Okamoto}^{8)}$ have also reported that larger elongated grains can be obtained with an increase in nitrogen content even in rephosphorized Al-killed steels. But no detailed studies have been disclosed yet.

It is well known that fine AlN called " preprecipitation cluster" during recrystallization plays a leading role in the formation of the recrystallization texture of Al-killed steels. So, in rephosphorized Al-killed steels, much consideration should be given to the interaction between phosphorus and AIN precipitation behavior.

In the present study, the heating rate dependence of $\bar{r}$-value, grain and texture in annealing was investigated first as it offers useful information on the AlN precipitation behavior during recrystallization. Next, the effect of phosphorus on the AlN precipitation rate and the recrystallization behavior was investigated. Finally, the formation mechanism of the recrystallization texture of rephosphorized Al-killed steels is discussed.

\section{Materials and Experiments}

The materials used were hot-rolled bands, $2.8 \mathrm{~mm}$ thickness, of three kinds of rephosphorized Al-killed steels (P: 0.06 0.07\%, Steels 1 3) with different contents of $\mathrm{Mn}$, sol.Al and $\mathrm{N}$, and of a conventional Al-killed steel (P: $0.016 \%$, Steel 4). The chemical compositions of these materials are shown in Table 1. All these hot-rolled bands were coiled at a low temperature to prevent AlN precipitation.

First of all, in order to investigate the heating rate dependence of $\bar{r}$-value of rephosphorized Al-killed steels, these hot bands were cold rolled $75 \%$ and annealed at $700{ }^{\circ} \mathrm{C}$ for $1 \mathrm{hr}$ at various heating rates of 20 to $440^{\circ} \mathrm{C} / \mathrm{hr}$. Then the $\bar{r}$-value was calculated with an equation $\bar{r}=\left(r_{0}+2 r_{45}+r_{90}\right) / 4$, where $r_{0}, r_{45}$ and $r_{90}$ correspond to the $r$-value at $15 \%$ uniaxial tensile straining in $0^{\circ}, 45^{\circ}$ and $90^{\circ}$ directions to the rolling direction, respectively. (200) pole figures (at 1/2 thickness) before annealing, microstructures, grain sizes, grain elongation ratios, X-ray integrated intensities (at 1/4 thickness) and (200) pole figures after annealing of Steels 1 and 4 were also measured to clarify the effect of phosphorus as these steels have almost the same chemical compositions except for phosphorus.

Next, the following experiments were conducted in Steels 1 and 4 to study the effect of phosphorus on the

Table 1. Chemical compositions of materials used. (wt \%)

\begin{tabular}{l|c|ccccc}
\hline \multicolumn{1}{c|}{ Steel } & No. & G & Mn & P & sol. Al & N \\
\hline \multirow{3}{*}{$\begin{array}{l}\text { Rephosphorized } \\
\text { Al-killed }\end{array}$} & 1 & 0.050 & 0.24 & 0.069 & 0.041 & 0.0052 \\
\cline { 2 - 6 } & 2 & 0.047 & 0.25 & 0.061 & 0.060 & 0.0056 \\
\cline { 2 - 6 } & 3 & 0.056 & 0.30 & 0.071 & 0.052 & 0.0047 \\
\hline Al-killed & 4 & 0.053 & 0.26 & 0.016 & 0.036 & 0.0057 \\
\hline
\end{tabular}

* Originally published in Tetsu-to-Hagané, 68 (1982), No. 9, Special Issue on High Strength Sheet Steels, 1228, in Japanese. English version received December 14, 1981. (C) 1982 ISIJ

** Fukuyama Laboratories, Technical Research Center, Nippon Kokan K. K., Kokan-cho, Fukuyama 721. 
AlN precipitation rate and the recrystallization behavior.

For the study on the AlN precipitation behavior, hot-rolled bands were prepared for the measurement of internal friction, soaked at $650^{\circ} \mathrm{C}$ for 10 to $70 \mathrm{~min}$ in a salt bath, air cooled, reheated at $350{ }^{\circ} \mathrm{C}$ for $1 \mathrm{hr}$ and furnace cooled to make the solute carbon precipitate completely, followed by the measurement of internal friction of nitrogen.

As to the study on the recrystallization behavior, the $75 \%$ cold-rolled specimens were picked up from the furnace during heating at a heating rate at which the $\bar{r}$-value shows the maximum value (hereinafter called "peak heating rate"). Changes in hardness (HR30T) and X-ray integrated intensity during heating from 500 to $700{ }^{\circ} \mathrm{C}$ were measured.

To make the effect of phosphorus more clear, the recrystallization texture and the recrystallization behavior were also studied in Steel 1 and 4 with AlN precipitated prior to cold rolling by heating hot-rolled bands at $930{ }^{\circ} \mathrm{C}$ for $10 \mathrm{~min}$.

\section{Results}

\section{Heating Rate Dependence of $\bar{r}$-value}

Figure 1 shows the heating rate dependence of $\bar{r}$ value of each steel. Rephosphorized Al-killed steels also have the heating rate dependence of $\bar{r}$-value with a peak heating rate characteristic to a conventional Al-killed steel.

Among some studies ${ }^{9-11)}$ on the heating rate dependence of Al-killed steels, Takahashi and Okamoto $^{11)}$ showed that a peak heating rate could be calculated by the following equation:

$$
\log (\mathrm{PHR})=18.3+2.7 \log ([\mathrm{Al}] \times[\mathrm{N}] \times[\mathrm{Mn}] / \mathrm{CR})
$$

where, PHR: Peak heating rate $\left({ }^{\circ} \mathrm{C} / \mathrm{hr}\right)$

CR: Cold reduction rate (\%)

[Al], [N], [Mn]: Content of sol. Al, N and $\mathrm{Mn}(\mathrm{wt} \%)$

It seems very useful to know whether the observed peak heating rate is in agreement with the calculated one by Eq. (1) in order to study the recrystallization behavior of Al-killed steels because a certain factor is supposed to affect the AlN precipitation behavior or the recrystallization rate if the observed peak heating rate is not subject to Eq. (1). Table 2 shows the comparison of a calculated peak heating rate with an observed one for each rephosphorized Al-killed steel. The observed peak heating rate coincides very well with the calculated one. Phosphorus, therefore, looks as if it had no effect on the AlN precipitation behavior or the recrystallization rate. However, the $\bar{r}$-value of Steel 1 is lower than that of Steel 4 at a peak heating rate though these two steels have almost the same chemical compositions other than phosphorus and have the same peak heating rate. This means phosphorus might have some unpreferable effect on the deep drawability, that is, on the recrystallization texture.

\section{Heating Rate Dependence of Grain and Texture}

The grain and texture of Al-killed steels also show the unique heating rate dependence corresponding to the $\bar{r}$-value. The heating rate dependence of grain and texture was studied in Steels 1 and 4 which have almost the same chemical compositions except for phosphorus and have the same peak heating rate.

Photograph 1 shows the microstructures. Figure 2 shows the results of grain size number and grain elongation ratio. A rephosphorized Al-killed steel shows the similar heating rate dependence of grain to a conventional Al-killed steel. That is, the largest elongated grain is obtained at a peak heating rate and smaller elongated grains at a heating rate slower than the peak heating rate. Smaller and more equiaxed grains are formed at a heating rate faster than the peak heating rate. However, the grain size and the grain elongation ratio of a rephosphorized Al-killed steel are smaller than those of a conventional one at every heating rate. Phosphorus, therefore, seems to reduce the AlN's effect on making elongated grains during recrystallization.

Figure 3 shows the heating rate dependence of $\mathrm{X}$ ray integrated intensity. A rephosphorized Al-killed steel shows the maximum $\{222\}$ intensity and the minimum $\{200\}$ and $\{110\}$ intensity at a peak heating rate as well as a conventional one. In comparison with the $\bar{r}$-value shown in Fig. 1, the effect of phosphorus on the $\{222\}$ intensity is in good agreement with that on the $\bar{r}$-value. Meanwhile, the effect of phosphorus on the $\{200\}$ and $\{110\}$ intensity is not always in agree-

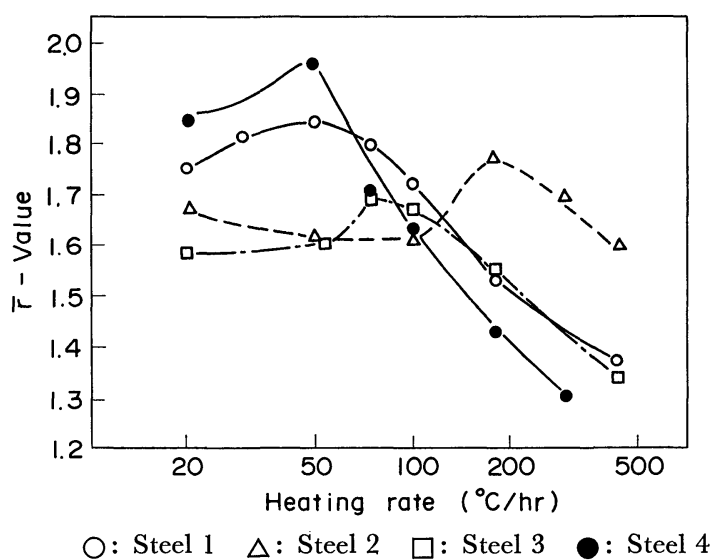

Fig. 1. Effect of heating rate on $\bar{r}$-value of Steels 1, 2, 3, and 4 , cold rolled $75 \%$, annealed at $700{ }^{\circ} \mathrm{C}$ for $1 \mathrm{hr}$.

Table 2. Comparison of a calculated peak heating rate with an observed one.

\begin{tabular}{|c|c|c|c|c|c|c|c|}
\hline Steel & No. & sol. Al & $\mathrm{N}$ & $\mathrm{Mn}$ & $\begin{array}{l}\text { GR } \\
(\%)\end{array}$ & $\begin{array}{l}\text { Calcd. } \\
\text { PHR } \\
\left({ }^{\circ} \mathrm{C} / \mathrm{hr}\right)\end{array}$ & $\begin{array}{c}\text { Obsd. } \\
\text { PHR } \\
\left({ }^{\circ} \mathrm{C} / \mathrm{hr}\right)\end{array}$ \\
\hline \multirow{3}{*}{ 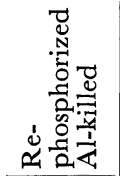 } & 1 & 0.041 & 0.0052 & 0.24 & 75 & 50 & 50 \\
\hline & 2 & 0.060 & 0.0056 & 0.25 & " & 180 & 180 \\
\hline & 3 & 0.052 & 0.0047 & 0.30 & " & 100 & 90 \\
\hline Al-killed & 4 & 0.036 & 0.0057 & 0.26 & " & 60 & 50 \\
\hline
\end{tabular}




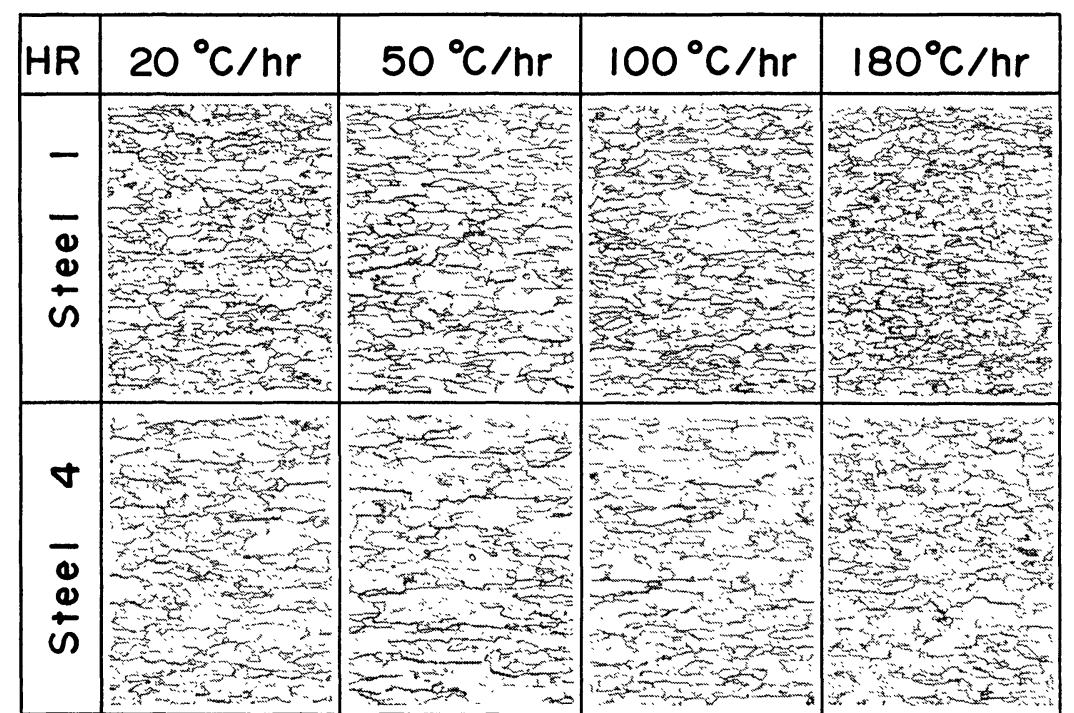

HR: Heating rate

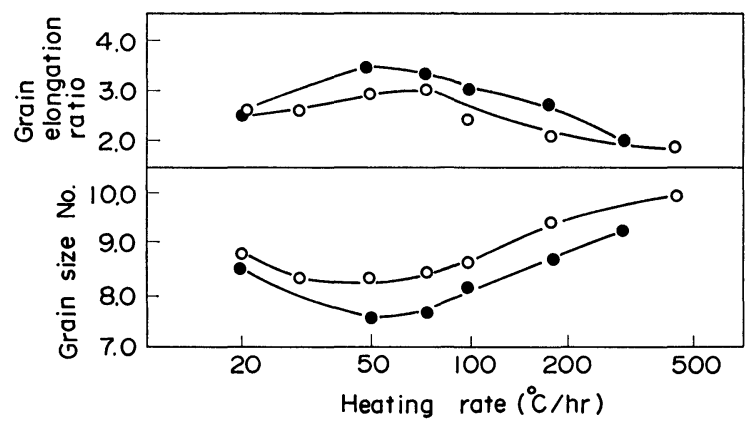

O: Steel 1 : Steel 4

Fig. 2. Effect of heating rate on grain size and grain elongation ratio of Steels 1 and 4, cold rolled $75 \%$, annealed at $700^{\circ} \mathrm{C}$ for $1 \mathrm{hr}$.

ment with that on the $\bar{r}$-value. The $\{200\}$ intensity of a rephosphorized Al-killed steel is higher than that of a conventional one at every heating rate. As for the $\{110\}$ intensity, no remarkable effect of phosphorus is observed both at the peak heating rate and at heating rates slower than the peak heating rate. However, at heating rates faster than the peak heating rate, a rephosphorized Al-killed steel has a lower $\{110\}$ intensity than a conventional one.

Figure 4 shows (200) pole figures after cold rolling. There is little difference in the cold-rolling texture between a rephosphorized Al-killed steel and a conventional one.

Figure 5 shows (200) pole figures after annealing. At every heating rate, the preferred orientation of a rephosphorized Al-killed steel is $\{111\}\langle 112\rangle$ though that of a conventional one is $\{111\}\langle 110\rangle$.

Figure 6 shows (200) pole figures after annealing for the specimens with AlN precipitation treatment in hot bands. In this case, the preferred orientation of a rephosphorized Al-killed steel is also $\{111\}\langle 112\rangle$ and different from that of a conventional one.

According to the results shown in Figs. 5 and 6, not only the interaction between phosphorus and AlN precipitation behavior, but also phosphorus itself

\section{$100 \mu m$} killed steel.
Photo. 1.

Effect of heating rate on microstructures of Steels 1 and 4 , cold rolled $75 \%$, annealed at $700{ }^{\circ} \mathrm{C}$ for $1 \mathrm{hr}$.

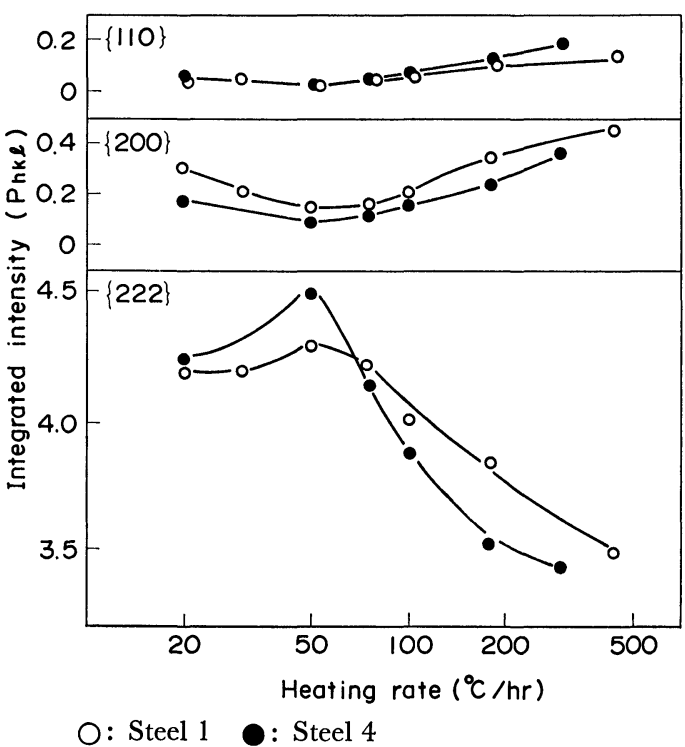

Fig. 3. Effect of heating rate on integrated intensity of Steels 1 and 4 , cold rolled $75 \%$, annealed at $700^{\circ} \mathrm{C}$ for $1 \mathrm{hr}$.

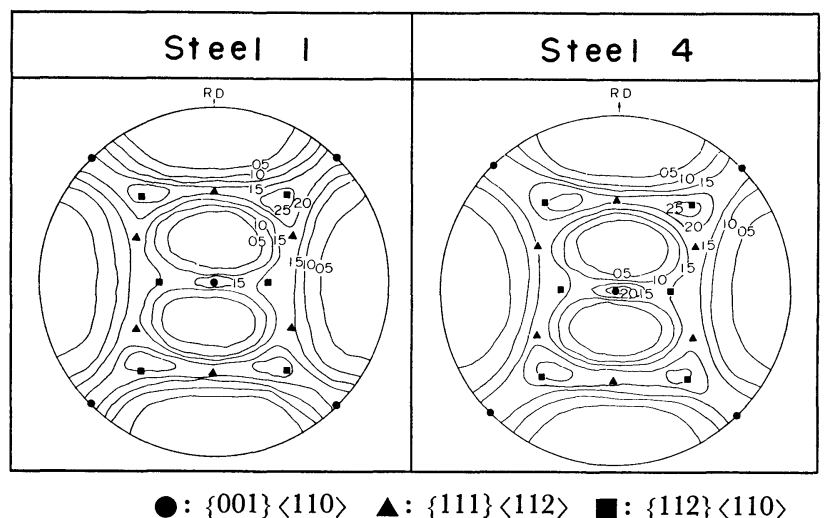

Fig. 4. (200) pole figures of Steels 1 and 4 before annealing, cold rolled $75 \%$

seems to play an important role in the formation of the recrystallization texture of a rephosphorized Al- 
$\Delta:\{111\}\langle 112\rangle$

$\square:\{111\}\langle 110\rangle$

Fig. 5.

(200) pole figures of Steels 1 and 4 after annealing, cold rolled $75 \%$, annealed at $700{ }^{\circ} \mathrm{C}$ for $1 \mathrm{hr}$.
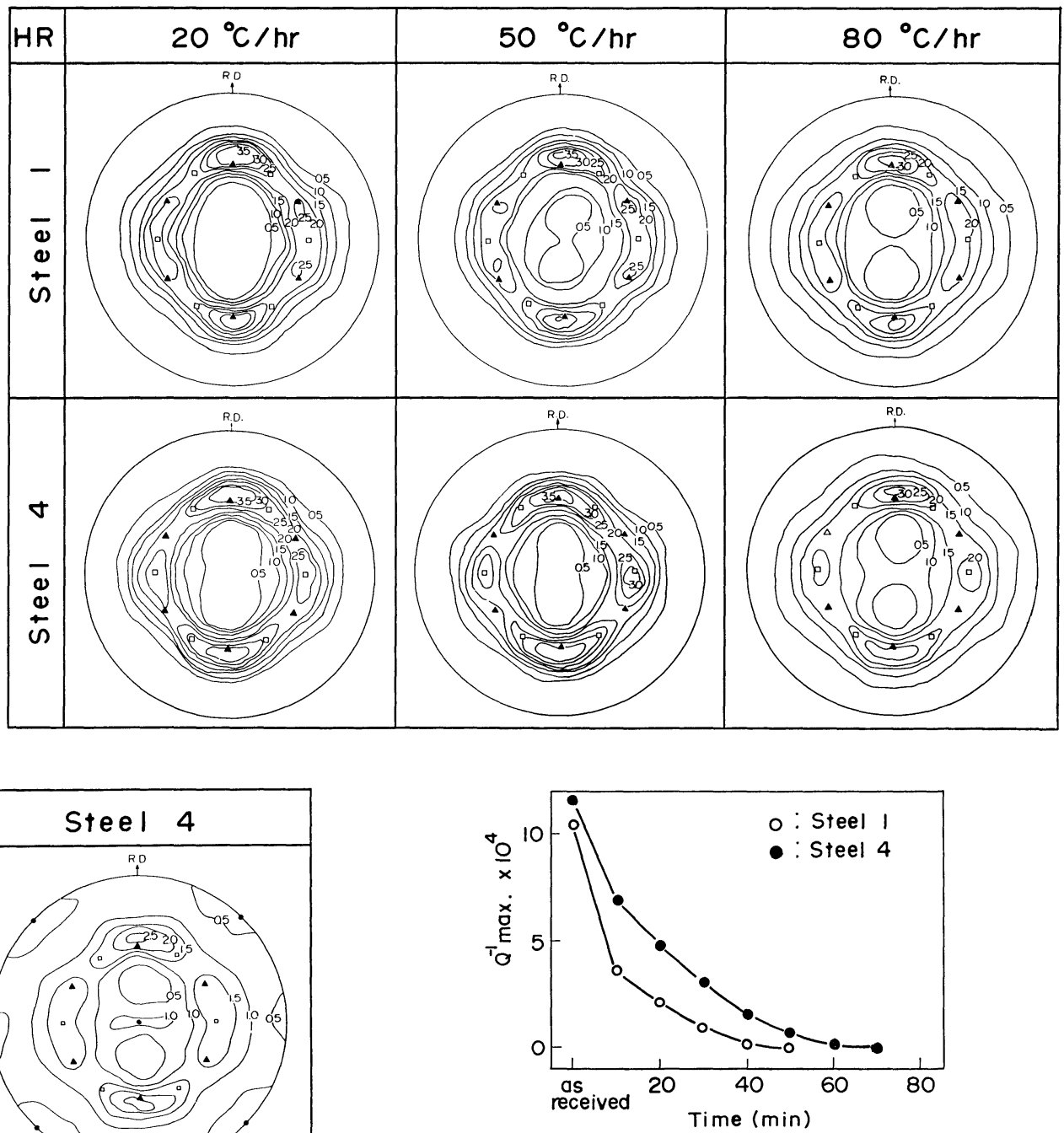

Fig. 7. AlN precipitation behavior in hot bands of Steels 1 and 4 at $650^{\circ} \mathrm{C}$ isothermal annealing.

work produces a slight increase in the rate of AlN precipitation. The result shown in Fig. 7, therefore, can not be applied as it is to the recrystallization stage. But the tendency of phosphorus to promote AlN precipitation is supposed to be maintained at the recrystallization stage.

It is very interesting that the peak heating rate of a rephosphorized Al-killed steel is subject to Eq. (1) even if phosphorus promotes AlN precipitation.

\section{Recrystallization Behavior}

As mentioned above, a rephosphorized Al-killed steel shows some characteristic phenomena due to the addition of phosphorus. So, to further clarify the effect of phosphorus, the recrystallization behavior of Steels 1 and 4 at the peak heating rate, at which the characteristics of Al-killed steels appear most markedly, was studied. The same study was also made on the specimens with AlN precipitation treatment in hot bands.

Figure 8 shows the change in hardness during heating. In comparison with the specimens with AlN precipitation treatment prior to cold rolling, the recrystallization is also retarded in a rephosphorized conventional one, especially at the early stage of precipitation. As discussed by Leslie et al., ${ }^{13)}$ the cold 


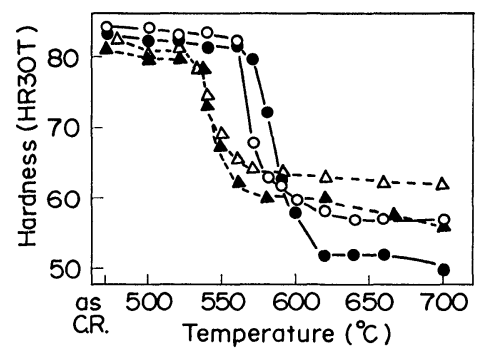

O, $\Delta:$ Steel $1 \quad$ O, $\Delta:$ Steel 4

$\Delta, \boldsymbol{\Delta}$ : Specimens with AlN precipitation treatment in hot bands

Fig. 8. Change in hardness of Steels 1 and 4 during continuous heating at a peak heating rate $50^{\circ} \mathrm{C} / \mathrm{hr}$.

steel as well as in a conventional one. But the recrystallization rate of a rephosphorized steel is a little faster than that of a conventional one. Meanwhile, no effect of phosphorus on the recrystallization rate is observed in the specimens with AlN precipitation treatment in hot bands. That is, phosphorus itself does not affect the recrystallization rate. Therefore, AlN is considered to play a role in retarding the recrystallization in a rephosphorized Al-killed steel as well as in a conventional one though phosphorus slightly weakens the retardation effect of AlN. According to these results, phosphorus might not only promote the AlN precipitation rate, as described in 3, but also affect the precipitation site of AlN.

Figure 9 shows the change in X-ray integrated intensity during heating. From the early stage to the middle of recrystallization, a rapid increase in the $\{222\}$ intensity, a rapid decrease in the $\{200\}$ intensity and a decrease in the $\{110\}$ intensity are observed in a rephosphorized Al-killed steel as well as in a conventional one. At the end of recrystallization, a rephosphorized Al-killed steel has a lower $\{222\}$ intensity and a higher $\{200\}$ intensity than a conventional one. There is little difference in the $\{110\}$ intensity between them.

These texture behaviors during recrystallization are quite different from those of the specimens with AlN precipitation treatment prior to cold rolling. This means, therefore, that AlN plays a leading role in the formation of the recrystallization texture of a rephosphorized Al-killed steel.

As for the X-ray intensity behavior of the specimens with AlN precipitation treatment prior to cold rolling, both a rephosphorized Al-killed steel and a conventional Al-killed steel show the same tendency as a rimmed steel. From the early stage to the middle of recrystallization, the $\{222\}$ intensity decreases, the $\{200\}$ intensity slightly increases and the $\{110\}$ intensity increases. From the middle to the end, the $\{222\}$ intensity increases and the $\{200\}$ intensity rapidly decreases. At the end of recrystallization, a rephosphorized Al-killed steel has higher $\{222\}$ and $\{200\}$ intensities and a lower $\{110\}$ intensity than a conventional one.

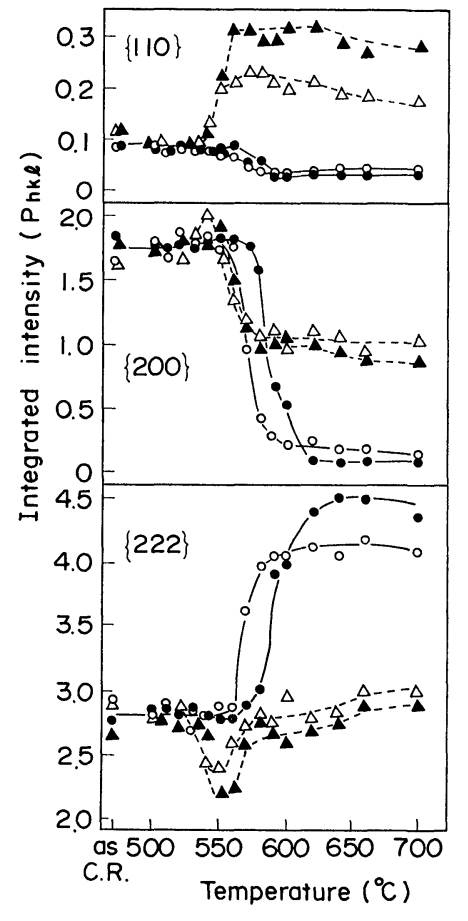

O, $\Delta:$ Steel $1 \quad \Delta, \quad$ Steel 4

$\Delta, \boldsymbol{\Delta}:$ Speciemens with AlN precipitation treatment in hot bands

Fig. 9. Change in integrated intensity of Steels 1 and 4 during continuous heating at a peak heating rate $50^{\circ} \mathrm{C} / \mathrm{hr}$.

\section{Discussion}

A rephosphorized Al-killed steel shows the following phenomena characteristic to a conventional Alkilled steel:

(1) The peak heating rate of $\bar{r}$-value is observed.

(2) Eleongated grains are obtained.

(3) The recrystallization is strongly retarded at the peak heating rate.

(4) The $\{111\}$ intensity increases and the $\{100\}$ intensity decreases rapidly from the early stage of recrystallization at the peak heating rate.

On the other hand, the following characteristics are observed by adding phosphorus:

(1) The preferred orientation changes from $\{111\}$ $\langle 110\rangle$ to $\{111\}\langle 112\rangle$, as compared with the conventional Al-killed steel with almost the same chemical compositions and the same peak heating rate, at the peak heating rate.

(2) Lower $\bar{r}$-value, smaller grain size and lower grain elongation ratio are obtained.

(3) The recrystallization rate is promoted a little.

(4) Low $\{111\}$ and high $\{100\}$ intensities are obtained.

Taking these results into account, the interaction between phosphorus and AlN precipitation behavior is supposed to play an important role in the formation of the recrystallization texture of a rephosphorized Alkilled steel. The effect of phosphorus on the AlN precipitation rate should be considered. As shown in Fig. 7, phosphorus promotes the AIN precipitation rate. If phosphorus has no effect on the AlN precipitation behavior other than on its precipitation rate, the peak 
heating rate is expected to shift to the faster one than the rate calculated by Eq. (1) as phosphorus itself does not affect the recrystallization rate. Because Eq. (1) means that the peak heating rate is determined by the balance between the AlN precipitation rate and the recrystallization rate. However, as shown in Table 2, the observed peak heating rate is in good agreement with the claculated one. So phosphorus seems not only to promote the AlN precipitation rate but also to weaken the retardation effect of AlN on recrystallization. A good agreement between the observed peak heating rate and the calculated one is considered to be caused by these effects of phosphorus on the AIN precipitation behavior. That is, the promotion of the AlN precipitation rate makes the peak heating rate fast and the weakening of the retardation effect of AIN on recrystallization makes it slow. The latter effect seems to be based on the effect of phosphorus on the precipitation site of AlN. Lower $\bar{r}$-value, smaller grain size, lower grain elongation ratio and faster recrystallization rate observed in a rephosphorized Al-killed steel are all supposed to be attributed to this phosphorus' effect on the precipitation site of AIN. And if phosphorus weakens the retardation effect of AlN on recrystallization, the severe restraint on nucleation other than the $\{111\}$ nucleus by AlN, which is usually observed in Al-killed steels, will be relieved, resulting in a decrease in the $\{111\}$ intensity and an increase in the $\{100\}$ intensity.

According to these discussions, it could be easily understood that the interaction between phosphorus and AIN precipitation behavior plays an important role in the formation of the recrystallization texture of a rephosphorized Al-killed steel. But due to this interaction alone, it is impossible to discuss the reason why the preferred orientation of a rephosphorized Alkilled steel is $\{111\}\langle 112\rangle$ and different from that of a conventional one.

Not only in the studies by $\mathrm{Hu}^{4)}$ and the present authors, ${ }^{6,7)}$ but also in the present study on the specimens with AlN precipitation treatment prior to cold rolling, phosphorus causes a shift of preferred orientation from $\{111\}\langle 110\rangle$ to $\{111\}\langle 112\rangle$. This suggests that phosphorus might have some special effect on the $\{111\}$ nucleation, independent of the interaction with $\mathrm{AlN}$. $\mathrm{Hu}^{4)}$ attributed the formation mechanism of the preferred orientation $\{111\}\langle 112\rangle$ to the interaction between phosphorus and sub-grain boundaries or grain boundaries during recrystallization. If phosphorus interacts with sub-grain boundaries or grain boundaries, the recrystallization ought to be retarded. However, in the present study on the specimens with AlN precipitated prior to cold rolling, as shown in Fig. 8, phosphorus has no effect on the recrystallization rate. It is, therefore, reasonable to suppose that the development of $\{111\}\langle 112\rangle$ should be attributed to the cold-rolling microstructures affected by phosphorus. As shown in Fig. 4, no remarkable effect of phosphorus is observed on the cold-rolling texture, but it seems possible that phosphorus may have some effect on the cold-rolling microstructures near the former grain boundaries which are regarded as nucleation sites of the $\{111\}$ orientation $^{14)}$ because phosphorus readily segregates onto the grain boundaries.

Taking these discussions into account, the formation mechanism of the recrystallization texture of a rephosphorized Al-killed steel is considered as follows: AlN controls the balance between the $\{111\},\{100\}$ and $\{110\}$ intensities at recrystallization through the interaction with phosphorus, and phosphorus itself affects the $\{111\}$ nucleation, especially its direction, independent of its interaction with AIN.

The present study was carried out in the rephosphorized Al-killed steel with a phosphorus content of about $0.07 \%$. The degree of the phosphorus' effect on the $\bar{r}$-value, the grain elongation ratio and so on is expected to change with an increase in phosphorus content. This suggests that all AlN which precipitate during recrystallization are not affected by phosphorus and some of them play the same role in a conventional Al-killed steel. And it seems that AIN which has an interaction with phosphorus contributes to the development of $\{111\}\langle 112\rangle$ and other AlN to the development of $\{111\}\langle 110\rangle$, because in the nucleation sites of $\{111\}\langle 112\rangle$, AlN is supposed to have more chances to interact with phosphorus and also to restrain nucleation other than the $\{111\}$ nucleus. However, AlN interacting with phosphorus restrains nucleation other than the $\{111\}$ nucleus less strongly than that without an interaction with phosphorus.

To summarize all these above-mentioned discussions, the following considerations could be given to the formation mechanism of the recrystallization texture of rephosphorized Al-killed steels. There are two kinds of AlN which play different roles during recrystallization; One interacts with phosphorus and develops the $\{111\}\langle 112\rangle$ orientation characteristic to a rephosphorized steel, the other develops the $\{111\}\langle 110\rangle$ characteristic to a conventional Al-killed steel. The former has a less retardation effect on recrystallization than the latter and so relieves the severe orientation-selectivity at nucleation. And this causes a decrease in the $\{111\}$ intensity, an increase in the $\{100\}$ intensity and a lower grain elongation ratio.

\section{Conclusions}

The present study was carried out to study the formation mechanism of the recrystallization texture of rephosphorized Al-killed high strength steels.

Consequently, the following results were obtained:

(1) A rephosphorized Al-killed steel has the same heating rate dependence of $\bar{r}$-value as a conventional Al-killed steel. And the largest grain elongation ratio is obtained at the peak heating rate.

(2) In comparison with the conventional Al-killed steel with almost the same chemical composition other than phosphorus and the same peak heating rate, a rephosphorized Al-killed steel shows lower $\bar{r}$-value due to a decrease in the $\{111\}$ intensity and an increase in the $\{100\}$ intensity, smaller grain size and lower grain elongation ratio at the peak heating rate.

(3) The preferred orientation of a rephosphorized Al-killed steel is $\{111\}\langle 112\rangle$ though that of a con- 
ventional Al-killed steel is $\{111\}\langle 110\rangle$. The same result is also obtained in the specimens with AlN precipitation treatment in hot bands.

(4) Phosphorus promotes the AlN precipitation rate and slightly weakens the retardation effect of AIN on recrystallization.

(5) In a rephosphorized Al-killed steel, AlN, which precipitates during recrystallization, plays a leading role in the formation of the recrystallization texture as well as in a conventional Al-killed steel. However, it is supposed that there are two kinds of AlN; one develops the $\{111\}\langle 112\rangle$ orientation through the interaction with phosphorus and the other develops the $\{111\}\langle 110\rangle$ orientation as it does in a conventional Al-killed steel. The former has a less retardation effect on recrystallization than the latter and so relieves the severe orientation-selectivity at nucleation.

\section{REFERENCES}

1) H. Yoshida, K. Sasaki and F. Kanzaki: IDDRG 3rd Biennial Congress, 1964, London.
2) S. Teshima and M. Shimizu: Mechanical Working of Steel, II, Gordon and Breach, New York, (1965), 279.

3) P. Wacquez and R. Van Daele: Sheet Metal Ind., 44 (1967), 21.

4) H. Hu: Texture of Cryst. Sol., 2 (1976), 113.

5) H. Hu: Texture of Cryst Sol., 4 (1980), 13.

6) K. Matsudo, K. Osawa and M. Sakoh: Tetsu-to-Hagané, 64 (1978), S722.

7) S. Ono, T. Shimomura, K. Osawa and K. Matsudo: Tetsu-to-Hagané, 67 (1981), S457.

8) M. Takahashi and A. Okamoto: Tetsu-to-Hagané, 65 (1979), S455.

9) M. Shimizu, K. Matsukura, N. Takahashi and Y. Shinagawa, Tetsu-to-Hagané, 50 (1964), 2094.

10) K. Matsudo: J. Japan Soc. Tech. Plasticity, 7 (1966), 376.

11) M. Takahashi and A. Okamoto: Sumitomo Metals, 27 (1975), 40.

12) W. Dickensheid and J. Brauner: Arch. Eisenhüttenw., 31 (1960), 531

13) W. G. Leslie, R. L. Ricket, G. L. Dotson and G. S. Walter: Trans. ASM, 46 (1954), 1470.

14) M. Matsuo, S. Hayami and S. Nagashima: Advan. X-ray Anal., 14 (1971), 214. 